\title{
República colonial chilena 1929-1973. Escuela e invisibilización del mapun- kimun del pueblo nación mapuche ${ }^{1}$
}

\author{
Colonial Republic of Chile 1929-1973. Escuela e invisibilización \\ del mapun-kimun del pueblo nación mapuche
}

\author{
República colonial chilena 1929-1973. Escola e \\ invisibilidade do mapun-kimun do povo
}

Recepción: 30/01/2020
Evaluación: 17/04/2020
Aceptación: 28/05/2020
Artículo de Investigación
https://doi.org/10.19053/01227238.11925

\section{RESUMEN}

El objetivo del estudio es analizar las implicancias que ha tenido la consolidación del Estado de Chile en territorio mapuche post ocupación del wajmapu, evento en el que la escuela chilena ha sido un dispositivo de control determinante para establecer un régimen educativo monocultural que invisibilizó el mapunkimun del pueblo mapuche. Originalidad: la idea de una república colonial en Chile no se encuentra desarrollada en la historia de la educación, en la que se reconstruyen los efectos de la violencia estatal en un marco de relaciones interculturales asimétricas. Método: es un trabajo de investigación cualitativa, con alcances descriptivos a través de un diseño de estudio documental que, empleando
Juan Mansilla Sepúlveda ${ }^{2}$ Universidad Católica de Temuco, Chile Grupo de investigación HISULA https://orcid.org/0000-0001-8175-7475 estrategias del trabajo con fuentes primarias y secundarias, permitió la revisión sistemática del corpus documental. Las conclusiones evidencian el reconocimiento del rol que cumplió la escuela para lograr la monoculturalidad e instalación de los saberes occidentales. No obstante, desde una historia cultural de largo plazo, la escuela como agencia estatal no logró su cometido, porque el mapunkimun del pueblo estado mapuche sobrevivió a todos los dispositivos de control e intentos de sometimiento y hoy mantiene esa resistencia cultural en un Estado que sigue operando desde lógicas excluyentes de la diversidad étnica y lingüística.

Palabras clave: Colonialismo; escuela monocultural; mapun-kimun; Estado de Chile.

1 Esta investigación se enmarca en el contexto del Proyecto FONDECYT n. ${ }^{\circ} 1191016$ titulado "Consolidación de la escuela monocultural en territorio mapuche, periodo post-reduccional (1929-1973). Colonialidad republicana e invisibilización del mapun-kimün".

2 Profesor de Estado en Historia, Geografía y Educación Cívica (Universidad de la Frontera, Temuco-Chile). Magíster en Desarrollo Regional y Local (Universidad Academia de Humanismo Cristiano-Santiago-Chile). Doctor en Filosofía y letras (Universidad Pontificia de Salamanca, Salamanca-España). Académico de la Facultad de Educación de la Universidad Católica de Temuco, Chile. Integrante Grupo de Investigación HISULA, Universidad Pedagógica y Tecnológica de Colombia. Correo electrónico: jmansilla@ uct.cl 
ABSTRACT

\begin{abstract}
The objective of the study is to analyze the implications that the State of Chile has had in its consolidation in Mapuche's territory after the occupation of the Wajmapu, where the Chilean school has been a determining control device to establish a monocultural educational regime that made the Mapuche people's mapunkimun invisible. Originality: The idea of a colonial republic in Chile is not developed in the education history, where the effects of state violence are reconstructed in an asymmetric intercultural relations framework. Method is a qualitative research work, with descriptive scope through a documentary study design, which, using work strategies with primary and secondary sources, allowed
\end{abstract}

the systematic review of the documentary corpus. The conclusions show the recognition of the role that the school played to achieve monoculturalism and installation of Western knowledge. However, from a long-term cultural history, the school as a state agency did not achieve its mission, because the mapun-kimun of the Mapuche state people survived all control devices and attempts at submission and today maintains that cultural resistance in a state that continues to operate from a logic that excludes the ethnical and linguistic diversity.

Key words: Colonialism; monocultural school; colonialism; mapunkimun; State of Chile.

\section{RESUMO}

O objetivo deste estudo é analisar os desdobramentos da consolidação do Estado do Chile no território mapuche após a ocupação do wajmapu, onde a escola chilena foi um dispositivo do controle determinante para estabelecer um regime educativo monocultural que invisibilizou o mapunkimun do povo mauche. Originalidade: a ideia de uma república colonial no Chile não se encontra desenvolvida na história da educação, na qual se reconstroem os efeitos da violência estatal em um marco de relações interculturais assimétricas. Método é um trabalho de pesquisa qualitativa, com alcances descritivos através de um desenho de estudo documental, que empregando estratégias do trabalho com fontes primárias e secundárias, permitiu a revisão sistemática do corpus documental. As conclusões mostram o reconhecimento do papel que a escola cumpriu para concretizar a monoculturalidade e instalação dos saberes ocidentais. Não obstante, a partir de uma história cultural de longa duração, a escola como agência estatal não cumpriu sua missão, porque o mapun-kimun do povo estado mapuche sobreviveu a todos os dispositivos de controle e tentativas de envio e atualmente mantém essa resistência cultural em um estado que segue operando com lógicas excludentes da diversidade étnica e linguística.

Palavras-chave: Colonialismo; escola monocultural; mapunkimun; estado de Chile.

\section{INTRODUCCIÓN}

\section{Antecedentes históricos relacionados con la "Ocupación de La Araucanía"}

A diferencia de los hechos ocurridos con la mayoría de los pueblos indígenas de América, las fuerzas militares del imperio español no lograron derrotar ni someter a los indígenas del centro-sur de Chile. Después de decenios de 
sangrienta guerra entre mapuches y españoles, desde el 4 de junio de 1536 (llegada de Diego de Almagro y sus huestes a Chile) hasta el 9 de enero de 1641, se pactó el cese de hostilidades en el denominado Tratado de Paz de Quilín. Este acuerdo reconoció el río Biobío como límite sur de la Capitanía General de Chile; se estableció que allí comenzaba la frontera entre el mundo hispano-criollo y el pueblo mapuche, el primero de una serie de pactos establecidos entre mapuches y españoles. Las ideas que se plasmaron en ese primer parlamento se mantuvieron por más de dos siglos. En total, se firmaron más de veinte pactos de este tipo, gracias a los cuales el pueblo nación mapuche siguió viviendo en forma relativamente autónoma de la dominación española en el territorio ubicado al sur del Biobío ${ }^{3}$.

Ciento setenta años después, en 1811, en condiciones más desventajosas para los mapuches, en el Parlamento de Concepción los principios y acuerdos del Tratado de Paz de Quilín fueron ratificados por los representantes de la naciente República de Chile. De esta forma el Wajmapu (territorio mapuche) conservó su autonomía territorial e independencia durante 242 años ${ }^{4}$. El último parlamento sostenido entre españoles y mapuches fue el de Negrete, en marzo de 1803. Este acuerdo fue firmado durante la última década del dominio español en Chile, que hasta 1810 dependió directamente del mando militar del Virreinato de Perú ${ }^{5}$.

En la segunda mitad del siglo XIX, los Estados de Chile y Argentina tomaron la decisión de incorporar a la fuerza el territorio habitado ancestralmente por el pueblo mapuche. En Chile, la integración de las antiguas provincias de Arauco, Valdivia y Llanquihue dio inicio a un proceso de ocupación de tierras fértiles donde terminan imponiéndose los proyectos modernizadores que propiciaron los grupos dirigentes oligárquicos del centro del país y la consiguiente política inmigratoria promovida para "mejorar la raza salvaje del indio"6.

En el siglo XIX el Estado de Chile derrotó al pueblo-nación mapuche con la misma estrategia ideada por los militares españoles, es decir, levantando fuertes militares en los bordes de los ríos. El militar chileno Cornelio Saavedra llamó a la maniobra "línea de Malleco", que básicamente consistió en reproducir lo construido por los hispanos en los bordes del río Biobío. Tanto Prieto como Bulnes, ambos hijos de militares españoles, desarrollaron en la primera mitad del siglo XIX un diseño similar durante los veinte años que gobernaron como clan familiar, siempre receptivos a las ideas de la oligarquía de Concepción. Posteriormente, en plena Guerra del Pacífico (1879-1883), Temuco fue fundado (1881) a partir de la acción de colonos nacionales y extranjeros, custodiados por el ejército de Chile

3 José Bengoa Cabello, El Tratado de Quilín. Documentos adicionales a la Historia de los antiguos mapuches del sur (Santiago de Chile: Catalonia, 2007), 45.

4 Jorge Calbucura, "La decolonización del saber y el ser mapuche: un caso de estudio al celebrarse el bicentenario de la construcción de la República de Chile", Polis. Revista Latinoamericana vol. 12, n. ${ }^{\circ} 35$ (2013): 411.

5 José Bengoa Cabello, comp., La memoria olvidada: historia de los pueblos indígenas de Chile (Santiago de Chile: Cuadernos Bicentenario de la Presidencia de la República, 2004), 273; María. Palumbo. "Educación En Movimientos Populares Rurales: Un Estado del Arte". Revista Historia de la Educación Latinoamericana vol.18 n. ${ }^{\circ} 26$, (2016) 219-40. https://doi.org/10.19053/01227238.4373.

6 Juan Mansilla Sepúlveda et al., "Instalación de la escuela monocultural en la Araucanía, 1883-1910: dispositivos de poder y Sociedad Mapuche”, Educação e Pesquisa vol. 42, n. ${ }^{1} 1$ (2016): 217. 
y la "Gendarmería de las colonias", cuyo jefe fue Hernán Trizano Avezzana. Luego de la resistencia mapuche, en 1868, a orillas del río Malleco, Benjamín Vicuña Mackenna dictó un discurso en el parlamento bajo el título "Conquista de Arauco", fundamentado en su libro publicado ese mismo año bajo el título Guerra a muerte. Lo anterior nos conduce a pensar que el comportamiento de las autoridades dirigentes de Chile fue similar a la de los gobernadores de Chile en el siglo XVI: una actitud de conquista con afanes colonizadores.

La ocupación representó una ruptura en la historia del pueblo nación-mapuche, desde la autonomía a la subordinación, y marca un punto de inflexión en la relación entre el Estado chileno y el pueblo mapuche. En ese momento, el Estado chileno logró generar "tierra sin indios" y, al mismo tiempo, "indios sin tierra"7.

Figura 1. "Carta general de colonización de la Provincia de Cautín"8

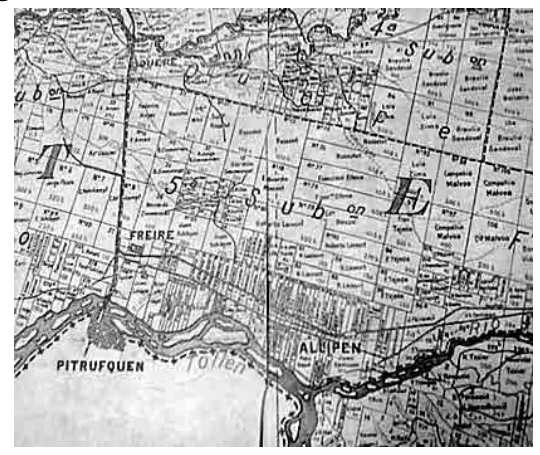

Fuente: Nicanor Boloña. Santiago: Tall. del Estado Mayor Jeneral, 1916, 68.

Unos de los resultados más dramáticos de la ocupación del Wajmapu fue la pérdida de las tierras por parte de las familias indígenas y su sentido comunitario, que se da en el lof-che (estructura política y social fundamental del pueblo mapuche a partir del parentesco). Concretamente, entre 1884 y 1927, en Chile los mapuches fueron confinados a unas tres mil reducciones. Cuarenta años más tarde, el número de reducciones indígenas llegó a dos mil. Dos causas originan la progresiva desaparición de las comunidades indígenas: la usurpación llevada a cabo por los latifundistas amparados por el Estado de Chile transformado en una república colonial, y la conversión de las comunidades indígenas: desde lof-che a resguardos indígenas según las lógicas occidentales impulsadas desde el Estado. Esta situación es el resultado de un proceso legislativo impulsado por y desde el Estado monocultural y colonialista de Chile, a través de una secuencia legislativa iniciada en 1927. Desde la perspectiva de la historia cultural, las premisas legales que el Estado implementó han tenido como objetivo deslegi-

7 Fernando Casanueva Valencia, "Indios malos en tierras buenas: visión y concepción del mapuche según las élites chilenas, siglo XIX, en Colonización, resistencia y mestizaje en las Américas. Siglos XVI-XX, ed. Guillaume Boccara (Quito: Abya-Yala, 2002), 291.

8 Archivo Regional de la Araucanía, Temuco. Inspección general de Colonización e Inmigración. Construida y dibujada por Nicanor Boloña. Escala 1:100.000. Santiago de Chile, septiembre de 1916. 
timar el fundamento jurídico del sistema de propiedad colectiva sobre la tierra (mapu) y asimilar al mapuche al canon occidental.

En este contexto, la escuela fue utilizada, a partir de la inserción intencional del vencido, aceptando "tácticamente" el concepto "araucano", sobre todo en el primer ciclo del movimiento mapuche, como símbolo de resistencia cultural y política. Es muy interesante esa dialéctica colonizador-colonizado. Se utilizan las instituciones y lenguajes de los vencedores para impulsar su propio proyecto de emancipación. Ese fue el sueño de Manuel Aburto Panguilef en la década de 1940 de crear una República Araucana, que además se dio en un contexto de procesos de descolonización, a partir de los hechos derivados de la descolonización afroasiática posteriormente a la Conferencia de Bandung, realizada en Indonesia en 1955.

\section{Leyes indígenas del Estado de Chile entre 1927 y 1952}

Durante la presidencia del primer gobierno de Carlos Ibáñez del Campo se promulgó la ley n. ${ }^{\circ} 4.169$ del 29 de agosto de 1967, que creó un Tribunal Especial Indígena, con sede en la ciudad de Temuco, capital de la provincia de Cautín. El objetivo era proceder a la división de las reservas mapuches que tuvieran "Títulos de Merced de Tierras" y solicitasen expresamente la división. El reglamento específico de esta ley, dictada el 4 de julio de 1928, explicitaba en su artículo número 3 que las peticiones de una división de una comunidad podrán ser formuladas verbalmente o por escrito, por cualquier indígena que sea cabeza de familia o con derechos individuales. El tribunal otorgaba preferencia, dentro de cada zona, a las divisiones que hubieren sido solicitadas por orden de fecha 9 .

De hecho, durante el gobierno de Carlos Ibáñez del Campo se dictó una ley que expropiaba terrenos indígenas para poder construir una escuela agrícola. De este modo, la ley n. ${ }^{\circ} 4.332$ de junio de 1928 permitía expropiar tierras mapuches, y la ley $\mathrm{n}{ }^{\circ} 4.457$, de noviembre del mismo año, permitía permutar las tierras indígenas. Fue así como se expropiaron más de 1400 hectáreas de tierra mapuche en Temuco, y sus ocupantes (indígenas mapuches) fueron reubicados de manera forzada en otros lugares de las provincias de Cautín y Valdivia.

Otra ley creada en ese periodo fue la n. ${ }^{\circ} 4.802$ del 24 de enero de 1930. Esta ley originó cinco juzgados indígenas para proceder a dividir a las comunidades. Los abogados eran nombrados por el gobierno con un sueldo de mil pesos mensuales. Los jueces, además, tenían la facultad de actuar como árbitros en las complejas contiendas legales que se producían. Los jueces estaban autorizados para hacer uso de las fuerzas de carabinero ${ }^{10}$ para cumplir sus resoluciones. Esta misma

9 Víctor Gavilán Pinto, La Nación mapuche. Puelmapu ka Gulumapu (Santiago de Chile: Ayun, 2007), 162.

10 Nombre de la policía chilena proveniente de los cuerpos de caballería que portaban un arma de fuego denominada "carabina". Creada el 27 de abril de 1927 bajo el lema de "orden y patria", actualmente es una dependencia administrativa del Ministerio del Interior de Chile. El cuerpo policial de Carabineros de Chile, con casi 93 años de historia, pasa por una circunstancia compleja tras las críticas a su gestión de las protestas desarrolladas en el marco del "Estallido social de Chile" del 18 de octubre de 2019. Sus acciones han mermado su prestigio a los niveles más bajos de los últimos años. La sombra de una supuesta vulneración "sistemática" de los derechos humanos planea sobre todas las fuerzas del Estado, acusadas por el Instituto Nacional de Derechos Humanos (INDH), de 
ley permitía a los mapuches arrendar sus tierras hasta por cinco años a personas no mapuches. Todas estas prescripciones jurídicas estaban orientadas a eliminar el sentido y la práctica de propiedad colectiva de las tierras indígenas.

Una de las últimas acciones del gobierno de Carlos Ibáñez el Campo (19271931), antes de renunciar y partir a la Argentina en julio de 1931, fue la ley $n{ }^{\circ}$ 4.111 del 12 de junio de 1931. Después de Ibáñez se produjo en Chile el breve periodo de la República Socialista (que solo duró doce días). La corte suprema llamó a elección nuevamente y resultó elegido presidente de la República de Chile, por segunda vez, el miembro del Partido Liberal, Arturo Alessandri Palma (1932-1938), quien había sido enviado al exilio por Ibáñez.

Podría afirmarse que la ley n. ${ }^{\circ} 4.111$ fue una de las primeras que evidencia un cambio en la mentalidad del legislador. Este nuevo marco legal permaneció en Chile durante quince años y derogó dieciocho decretos y leyes indígenas que estuvieron vigentes entre 1853 y 1927, cuya pretensión había sido aniquilar al pueblo mapuche, reflejando ciertos rasgos genocidas. Tres fueron los cambios más relevantes de este nuevo corpus jurídico: (1) Ya no se podía dividir la tierra con la simple petición de un miembro de la comunidad, (2) el artículo segundo de esta ley establecía que la petición de división de la tierra debía solicitarla una tercera parte de los miembros de la comunidad, y (3) estableció la restitución de tierras a los mapuches y también la radicación de indígenas en tierras fiscales disponibles.

Posteriormente, aparece la ley n..$^{\circ} 7.864$ del 12 de septiembre de 1944, promulgada durante el gobierno radical de Juan Antonio Ríos Morales (1942-1946). Dejó exento de pago de contribuciones a todas las comunidades mapuches que se mantenían en estado de indivisión. Además, se condonaron todas las deudas atrasadas hasta 1944. Durante el gobierno radical de Gabriel González Videla (1946-1952) no hubo mayores novedades respecto a legislación indígena. Mantuvo la disposición de un tercio de los comuneros para dividir la comunidad indígena ${ }^{11}$.

Durante el segundo periodo presidencial de Carlos Ibáñez del Campo (19521958), el pueblo mapuche se encontraba en condiciones de extrema pobreza, tierras insuficientes, abusos y ambigüedades jurídicas en la división de propiedades, principalmente. El marco jurídico del derecho común chileno es aplicado sin ningún indicio de reconocimiento intercultural por parte del Estado colonial, lo que se traducía en exigencias tributarias para los mapuches, convertidos forzosamente en campesinos y ganaderos. Las parcelas no lograban una productividad óptima, y no contaban con ayuda técnica o asesorías en estas materias desde el gobierno. En este contexto, el gobierno de Ibáñez aprobó el decreto n. ${ }^{\circ}$ 12 del 9 de marzo de 1953 mediante el cual se establecía que la propiedad indígena que había sido dividida quedaba exenta del pago de impuestos y contribuciones por un plazo de diez años. Del mismo modo, esta ley mandataba que

causar más de 3460 heridos (357 con heridas oculares) desde que empezó la crisis social el 18 de octubre (https://www.publico.es/ internacional/carabineros-chile-crisis-reputacion-policia-horas-bajas.html).

11 Gavilán Pinto, La Nación mapuche, 163. 
los departamentos de Curacautín y Lautaro dejaran de pertenecer al Juzgado de Indios de Victoria, y pasaran a la jurisdicción de Temuco, capital de la provincia de Cautín. Otro decreto del gobierno de Ibáñez, publicado el 2 de abril de 1953, creó la Dirección de Asuntos Indígenas, dependiente del Ministerio de Tierras y Colonización, organismo que tendría a su cargo la supervisión del cumplimiento de la nueva ley indígena.

En definitiva, entre 1929 y 1973, fase "post-ocupación-reducción", la población mapuche se acercó a la sociedad chilena de manera obligada. Pero no solamente fue el agenciamiento jurídico un eficiente dispositivo de poder y control, sino la escuela y los internados misionales, ya que la derrota militar, territorial y política los había transformado en "ignorantes" y los dejaba en medio de una sociedad hegemónica que no entendían ${ }^{12}$. No solo estaban aislados en las reservas debido a la reducción de sus tierras, sino también respecto de los nuevos códigos sociales y culturales ${ }^{13}$.

Por lo expuesto, el aprendizaje del idioma del vencedor adquirió una importancia creciente y en ello la escuela cumplió un rol fundamental, eminentemente colonizador ${ }^{14}$. Fue el mismo Pascual Coña quien dio a entender que cada vez que se abría la posibilidad de profundizar su permanencia en el sistema educacional chileno, era alegría franca y profunda que lo conmovía por completo ${ }^{15}$.

En este periodo, algunos lonkos (jefes de una comunidad mapuche) entregaron a uno o más de sus hijos hombres para que fuesen instruidos en el sistema de educación nacional. En este sentido, entrar en alianza con las misiones y con la escuela era un modo de atenuar la ansiedad que significaba desconocer las capacidades e intenciones reales de un enemigo declarado ${ }^{16}$. En el periodo post-reduccional que vivieron los mapuches, la escuela no fue un espacio donde dialogaran los saberes y se lograra una simetría epistemológica en su relación con el sistema de conocimiento de las ciencias occidentales difundidas en y desde la escuela, y se avanzara en la búsqueda de soluciones a problemas específicos y locales ${ }^{17}$. Más bien predominaron prácticas y actitudes coloniales y racistas, que minorizaron los saberes y conocimientos indígenas ${ }^{18}$. En la Araucanía, en el periodo post-reduccional, la tarea de construir identidad nacional no solo iba dirigida hacia los indígenas, también era necesario hacerlo con sus propios nacionales (chilenos) y actuar con inmigrantes extranjeros que arribaban

12 Andrés Donoso Romo, Educación y nación al sur de la Frontera: Organizaciones mapuche en el umbral de nuestra contemporaneidad, 1880-1930 (Santiago de Chile: Pehuén, 2010), 124.

13 Sol Serrano Pérez, Macarena Ponce de León Atria y Francisca Rengifo, eds., Historia de la Educación en Chile (1810-2010). Tomo II: La educación nacional (1880-1930) (Santiago de Chile: Taurus, 2012), 210.

14 José Bengoa, Historia de los antiguos mapuches del sur. Desde antes de la llegada de los españoles hasta las paces de Quilín (Santiago de Chile: Catalonia, 2003), 235.

15 Susan A. Foote Wetherbee, Pascual Coña: Historias de sobrevivientes. La voz en la letra y la letra en la voz (Concepción: Editorial Universidad de Concepción, 2012), 101.

16 Serge Gruzinski, La colonización de lo imaginario: Sociedades indígenas y occidentalización en el México español. Siglos XVI-XVIII (México: Fondo de Cultura Económica, 1991), 234.

17 Juan Mansilla Sepúlveda y Claudia Huaiquián Billeke, "Enseñanza a la alemana: Transferencia del modelo de escuela de Berlín a Chile a fines del siglo XIX”, Revista Espacios vol. 17, n. ${ }^{\circ} 39$ (2018): 4.

18 Fidel Tubino Mongilardi, "El nivel epistémico de los conflictos interculturales", Revista Electrónica Construyendo Nuestra Interculturalidad, n. $^{\circ} 7$ (2011): 10. 
masivamente al territorio ${ }^{19} \mathrm{y}$, en este cometido, la escuela - ya fuera misional o pública - tuvo un papel preponderante ${ }^{20}$.

\section{Marco teórico}

\section{La escuela como agencia colonizadora}

Históricamente, la escuela ha sido considerada como una de las principales estrategias políticas utilizadas por el Estado para concretar procesos de colonización y ocupación territorial ${ }^{21}$ ya que bajo su idea modernizadora, en nombre de la ilustración y el progreso, va excluyendo los imaginarios propios, multiplicidades, subjetividades y contingencias de las formas concretas del mundo de la vida de las poblaciones locales, sobre todo si estas son indígenas ${ }^{22}$. De este modo, la escuela se constituyó como un dispositivo de saber-poder y control, mediante el cual el Estado chileno reconoció la otredad a través de una lógica binaria que reprimía las diferencias ${ }^{23}$. Desde una perspectiva pedagógica, se ha estudiado que la presencia de la escuela monocultural en la población mapuche ha generado el surgimiento de conflictos sociocognitivos en la formación de una identidad individual y social ${ }^{24}$, subvaloración económica ${ }^{25}$, hegemonización del sistema de saberes, pérdida de la lengua materna, distanciamiento con la cultura de referencia ${ }^{26}$, contradicción entre el saber escolar y la tradición oral sustantiva de las comunidades ${ }^{27}$.

A principios del siglo XX, el Estado de Chile pretendió que los mapuches, los colonos nacionales y los colonos extranjeros se fundieran en una sociedad culturalmente homogénea, al amparo de una educación monocultural ${ }^{28}$.Cuando el Estado chileno invadió la Araucanía, diversos agentes creyeron que con ese hecho finalizaba la denominada "guerra mapuche" y se inauguraba un próspero periodo de progreso similar al que tenía lugar en el resto de Chile, gracias a

19 Mansilla y Huaiquián, "Enseñanza a la alemana", 7.

20 Ingrid de Jong y Antonio Escobar Ohmstede, eds Las poblaciones indígenas en la conformación de las naciones y los Estados en la América Latina decimonónica (Ciudad de México: El Colegio de México / Centro de Investigaciones y Estudios Superiores en Antropología Social / El Colegio de Michoacán, 2016), 234.

21 Rosamel Millamán Reinao, "Relaciones interraciales e interétnicas de mapuches con no mapuches", en Rostros y fronteras de la identidad, comp. Mario Samaniego y Carmen Gloria Garbarini (Temuco: Pehuén editores, 2010), 34.

22 Segundo Quintriqueo Millán y Margaret McGinity Travers, "Implicancias de un modelo curricular monocultural en la construcción de la identidad sociocultural de alumnos mapuches de la IX Región de la Araucanía, Chile”, Estudios Pedagógicos vol. 35, n. ${ }^{\circ} 2$ (2009): 180.

23 Santiago Castro-Gómez, La poscolonialidad explicada a los niños (Popayán: Editorial Universidad del Cauca / Universidad Javeriana, 2005), 98 .

24 José Quidel Lincoleo, “El quiebre ontológico a partir del contacto mapuche hispano”, Chungara - Revista de Antropología Chilena vol. 48, n. ${ }^{\circ}$ (2016): 718.

25 Julio Paillalef Lefinao, Los mapuche y el proceso que los convirtió en indios (Santiago de Chile: Universidad Tecnológica Metropolitana, 2003), 106.

26 Miquel Essomba Gelabert, Construir la escuela intercultural: reflexiones y propuestas para trabajar la diversidad étnica y cultural (Barcelona: Graó, 1999), 112.

27 Daniel Quilaqueo Rapiman, Segundo Quintriqueo Millán y Prosperino Cárdenas Cárdenas, eds., Educación, currículum e interculturalidad: Elementos sobre formación de profesores en contexto mapuche (Santiago de Chile: Frasis, 2005), 123.

28 Mansilla Sepúlveda et al., "Instalación de la escuela monocultural". 
la instalación de instituciones estatales donde la escuela fue particularmente gravitante en la configuración de una nueva realidad sociocultural ${ }^{29}$. En esas escuelas e internados que comenzaron a surgir y distribuirse por el Wajmapu, se desarrolló un intenso proceso formativo de moralización y enseñanza práctica, se formarían sujetos disciplinados y productivos para que fueran útiles a las demandas de la sociedad chilena ${ }^{30}$.

Figura 2. "Niños civilizados y niños incivilizados", convento de Santa Magdalena de Altötting, provincia de Baviera (Alemania)

Reverso de la fotografía ${ }^{31}$
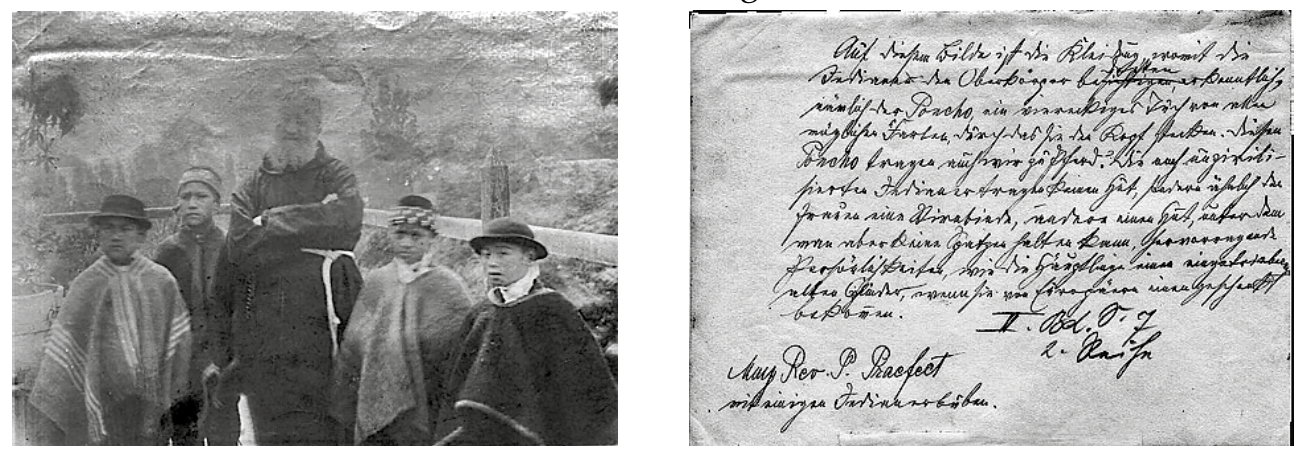

Fuente: Juan Mansilla Sepúlveda et al., La cruz capuchina en territorio mapuche. Educación y memoria fotográfica en Altötting, Alemania (Santiago de Chile: Pehuén, 2020).

La escuela pública, así como la instrumentalización estatal de las escuelas misionales católicas y protestantes, desde su origen fracasó en su contribución para el encuentro armónico entre los grupos que compartieron la vida en las despojadas tierras mapuches. Una información que probó cuán mixta era la composición demográfica de ese territorio fue proporcionado por el Censo de los Indios Araucanos, levantado en 1907. Era la primera vez que el Estado contaba a la población según sus características culturales, detallándose la cantidad de población por provincias y comunas de Chile. En el territorio de la Frontera (en la dictadura de Augusto Pinochet se denominará oficialmente Araucanía) el total de indígenas (mapuches) ascendió a 101118 personas: en Arauco 4706; en Malleco 12 259; en Cautín 46 781; en Valdivia 26 134; en Osorno y Carelmapu 11 358. Si bien las cifras estaban sobrerrepresentadas, es interesante relevar el planteamiento del misionero capuchino Jerónimo de Amberga, quien escribió que,

29 Jorge Pinto Rodríguez, De la inclusión a la exclusión: La formación del Estado, la nación y el pueblo mapuche (Santiago de Chile: Idea, 2001), 145.

30 Donoso Romo, Educación y nación.

31 Texto del reverso: AufdiesemBildeist die Kleidung, womit die Indianer den Oberkörperbedecken, erkenntlich, nämlich der Poncho, einviereckigesTuch von allenmöglichenFarben, durch das sie den Kopfstecken. Die nochunzivilisiertenIndianertragenkeinenHut (J.U.: Restunlesbar). Muy Rev. P. PraefectmithiesigenIndianerbuben. [En esta foto se ve la vestimenta con la cual los indígenas cubren la parte superior de su cuerpo, el poncho que es un paño cuadrangular de todos los colores por el cual meten la cabeza. Nosotros también usamos este poncho cuando montamos a caballo. Los indios todavía incivilizados no llevan sombrero. Muy Reverendo Padre Prefecto (Alexius) con niños indígenas de acá. (Traducción de Johana Umbach)]. 
por temor, muchos indígenas se negaron a responder y que los encuestadores no llegaron a todas partes ${ }^{32}$.

Los resultados sorprendieron a los chilenos, ya que pensaban que los mapuches ya no existían o eran muy pocos, lo que, entre otras razones, justificó aún más la instalación de una escuela monocultural definida como chilena, castellanizadora, obligando a niños y niñas de las localidades, indígenas y chilenos, a aprender solo en castellano ${ }^{33}$. La implementación curricular en las escuelas públicas y misionales significó un proceso doloroso, traumático, y, en definitiva, trágico para el pueblo-nación mapuche ${ }^{34}$.

En términos generales, se bloqueó la autodeterminación cognitiva del mapunkimün, entendido como un conjunto de coordenadas ontológicas, éticas y epistemológicas que permiten la emergencia del idioma mapunzugun como cuerpo activo y consensuado de conocimientos por la experiencia transgeneracional del pueblo mapuche ${ }^{35}$. El mapun-kimünes, la conceptualización de las experiencias y aprendizajes que se obtienen de espacios, personas, fenómenos particulares (waw, wigkul, por ejemplo) comprensibles desde la cultura mapuche, no fueron vistos o fueron minorizados con relación a la epistemología dominante o permitida desde la escuela monocultural y colonial. No obstante, en algunos lof-che se mantuvo el küpalme, es decir, la transmisión intergeneracional del conocimiento y del actuar en un campo cognitivo-comunicativo, pese al desplazamiento del mapunzugun ${ }^{36}$.

En el periodo post-reduccional, la escuela chilena enseñó a todos sus niños, niñas y jóvenes similares contenidos a partir de lo que se podría denominar colonialidad republicana, que sublimó la diversidad cultural, preferentemente de sus grupos originarios, e intentó eliminar la diferencia a través de la pretensión de universalidad del conocimiento y de los puntos de vista. El constructo colonialidad republicana es una expresión específica que permite aproximarnos críticamente a la consolidación de la presencia de las formaciones estatales modernas en territorios indígenas ${ }^{37}$, que cuestiona a la historiografía tradicional que da por concluidos los procesos de colonización con las independencias políticas americanas ${ }^{38}$. Se asume que la colonialidad y el espíritu colonial siguieron vigentes en manuales de enseñanza y textos escolares, en la cultura reglamentada, ritos y celebraciones patrias, en la autoimagen de los pueblos

32 Jerónimo de Amberga, "Estado intelectual, moral y económico del araucano", Revista Chilena de Historia y Geografía vol. 7, n. ${ }^{\circ} 11$ (1911): 23 .

33 Teresa Durán Pérez, Desiderio Catriquir Colipan y Arturo Hernández, comps., Patrimonio cultural mapuche: Derechos sociales y patrimonio institucional mapuche (Temuco: Universidad Católica de Temuco, 2007), 87.

34 Gabriel Pozo Menares, ed., Expoliación y violación de los derechos humanos en territorio mapunche. Cartas del padre Sigifredo, Misión de Panguipulli, año 1905 (Santiago de Chile: Ocho Libros, 2018), 328.

35 Rodrigo Becerra Parra y Gabriel Llanquinao Llanquinao, eds., Mapun kimün. Relaciones mapunche entre persona, tiempo y espacio (Santiago de Chile: Ocho Libros, 2018), 67.

36 Quidel Lincoleo, "El quiebre ontológico".

37 André Menard Poupin y Jorge Pavez Ojeda, eds., Mapuche y anglicanos. Vestigios fotográficos de la Misión Araucana de Kepe, 18961908 (Santiago de Chile: Ocho Libros, 2007), 121.

38 Linda Tuhiwai Smith, A descolonizar las metodologías: Investigación y pueblos indígenas (Santiago de Chile: LOM ediciones, 2016), 48. 
y aspiraciones de los sujetos ${ }^{39}$; también en las prácticas pedagógicas a través de las cuales los profesores actuaban como verdaderos gendarmes ideológicos al servicio de los poderes hegemónicos del Estado vencedor. De este modo, la "colonialidad" representa una gran variedad y complejidad de fenómenos que abarcan dimensiones desde lo psicológico y existencial hasta lo económico y militar, y que tienen una característica común: la determinación y dominación de uno por otro ${ }^{40}$, en el campo de la cultura, cosmovisión, filosofía, religiosidad y un modo de vivir por otros del mismo tipo ${ }^{41}$. La colonialidad pone en evidencia una epistemología de sujeto (activo) y objeto (pasivo) que puede reproducirse en los niveles de subalternidad: docilidad y buen encausamiento de los cuerpos y almas, disciplinamiento de la vida íntima, lo que deriva en la constitución de un invisible y fuerte "colonialismo interno". En otras palabras, se re-constituye el poder colonial de antes ("Europa"), el cual ya no necesita imponer sus ideas, las relaciones de poder que se orientan en características de raza y género, sino que el 'poder satelital', la nueva burguesía políticamente independizada, se encarga de mantener y perpetuar el mismo orden colonial ${ }^{42}$. Huelga, en consecuencia, la necesidad de reconocer a la institución escuela como una de las agencias de ese proceso de colonialización, para avanzar hacia la comprensión y práctica de la interculturalidad como clave de análisis de la ineludible integración cultural entre indígenas y chilenos $\mathrm{y}$, desde la interculturalidad, aportar hacia una mayor justicia social y mejores oportunidades de los pueblos originarios.

No obstante lo anterior, simultáneamente a estas reestructuraciones en los mecanismos de gobernanza colonial, las organizaciones mapuches y sus demandas parecen tener un quiebre en las últimas dos décadas. Esto se ha hecho evidente con la emergencia de nuevas formas políticas de lucha, que apuntan a la restitución de las "tierras antiguas" - no reconocidas en los Títulos de Merced-, la generación de autonomías de facto y al control del territorio mapuche histórico como un territorio en tanto primera nación. Este tipo de lucha se hizo evidente una vez no resueltas las demandas históricas con las cuales se había intentado negociar en los Acuerdos de Nueva Imperial ${ }^{43}$, en el primer gobierno postdictatorial, encabezado por Patricio Aylwin de la centroizquierdista Concertación de Partidos por la Democracia. Este quiebre comenzó a visualizarse cuando las

39 Carolina Ortiz, "Felipe Guamán Poma, Clorinda Matto de Turner, Trinidad Enríquez y la teoría crítica”, en Des/colonialidad y Bien Vivir. Un nuevo debate en América Latina, ed. Aníbal Quijano Obregón (Lima: Editorial Universidad Ricardo Palma, 2014), 123.

40 Boaventura de Sousa-Santos, Conocer desde el Sur: Para una cultura política emancipatoria (La Paz: CIDES-UMSA / CLACSO / Plural, 2008), 45.

41 Josef Estermann, “Colonialidad, descolonización e interculturalidad. Apuntes desde la Filosofía Intercultural”, Polis: Revista Latinoamericana vol. 13, n. $^{\circ} 38(2014): 360$.

42 Freya Schiwy “¿Intelectuales subalternos?: notas sobre las dificultades de pensar en diálogo intercultural”, en Indisciplinar las ciencias sociales. Geopolíticas del conocimiento y colonialidad del poder. Perspectivas desde lo andino, eds. Catherine Walsh, Freya Schiwy y Santiago Castro-Gómez (Quito: Abya-Yala / Universidad Andina Simón Bolívar, 2002), 123.

43 El Acta de Imperial, firmada entre el candidato presidencial de la Concertación en diciembre de 1989, Patricio Aylwin, y un nutrido y representativo elenco de dirigentes de los pueblos originarios dio origen a unos compromisos mutuos que fueron determinantes tanto en la política indígena de los gobiernos de la Concertación como en la actitud inicial hacia ellos de la mayor parte de los dirigentes y organizaciones mapuche. La elección del lugar del encuentro seguramente no fue fruto del azar. La Nueva Imperial fue refundada en 1882 en el lugar en que el conquistador Pedro de Valdivia había erigido un fuerte y una población en 1551, en la región con mayor concentración de población indígena que encontró en su penetración a la Araucanía, y la bautizó como La Imperial. 
comunidades mapuche iniciaron la recuperación de territorios ancestrales que estaban en propiedad de empresas forestales y de particulares, en la segunda mitad de la década de 1990. Esta ala del movimiento mapuche se enmarca dentro de un contexto contemporáneo en Latinoamérica, de resistencia de los pueblos indígenas frente a la agudización de los conflictos históricos que empresas y gobiernos reproducen, en el marco del patrón extractivista neoliberal, sobre territorios y relaciones sociales ${ }^{44}$.

En este orden de ideas, la escuela monocultural ha desempeñado un rol gravitante en la función de chilenizar a la población indígena a través de la transmisión de conocimiento, así como valores, normas y rituales colectivos, además de la difusión de símbolos y sentido de pertenencia a una comunidad diferente. En este contexto, se lleva a cabo un proceso de intervención que pretende uniformar, pero que no logró la integración ${ }^{45}$.

De este modo, el Estado chileno estableció con el pueblo nación mapuche, y particularmente, relaciones de carácter asimétrico y de imposición cultural hegemónica, materializando las funciones reproductoras de la escuela sobre la base de la arbitrariedad cultural, la imposición de símbolos, el lenguaje y los modos de vida propios de los sectores dominantes y ajenos a la generalidad de quienes asistían a las aulas ${ }^{46}$. En esta lógica, a principios del siglo decimonónico, posteriormente a la extensión territorial y numérica de las escuelas fiscales y misionales, el wajmapu estuvo marcado por la construcción - desde la escuela de la convivencia de una diversidad de procedencias y acervos culturales, étnicos e idiomáticos, propios de aquellos que habitaban un "nuevo territorio" y "una nueva realidad socialmente en construcción"; la presencia de niños y niñas de ascendencia mapuche, criolla o europea constituía una situación que debía ser atendida con urgencia con el propósito de formar a los futuros ciudadanos de la patria en que la identidad nacional chilena fuera uno de los rasgos más característicos en el marco de una diversidad social y cultural ${ }^{47}$.

La educación y la religión fueron los dispositivos que ayudaron a la inserción social del mapuche sobreviviente de acuerdo con un modelo homogeneizador ${ }^{48}$, instrumento de uniformización y disciplinamiento radical ${ }^{49}$. Así las cosas, la promulgación de la Ley de Enseñanza Obligatoria en 1920, obligó que la escuela primaria fuera obligatoria para todos los niños y niñas entre 6 y 13 años, basando el sistema educativo en la escuela monocultural. En este periodo, la escolarización de la población mapuche se caracterizó por la "negación" y "ocultación".

\footnotetext{
44 Héctor Nahuelpan Moreno y Jaime Antimil Caniupán, "Colonialismo republicano, violencia y subordinación racial mapuche en Chile durante el siglo XX”, Historelo. Revista de historia regional y local vol. 11, n. 21 (2019): 240.

45 Daniel Llanoavil Llancavil et al., "La función reproductora de la escuela en la Araucanía, 1883-1910", Revista Austral de Ciencias Sociales, n. 28 (2015).

46 Pierre Bourdieu y Jean-Claude Passeron, Los herederos. Los estudiantes y la cultura (Buenos Aires: Siglo XXI, 2008), 111.

47 Jaime Flores Chávez y Alonso Azócar Avendaño, Evangelizar, civilizar y chilenizar a los mapuches. Fotografías de la acción de los misioneros capuchinos en la Araucanía (Temuco-Sevilla: Ediciones Universidad de La Frontera / Editorial Universidad de Sevilla, 2015), 98.

48 Andrea Szulc, "Concepciones de niñez e identidad en las experiencias escolares de niños mapuche del Neuquén, Anthropologica vol. 33, n. ${ }^{\circ} 35$ (2015): 247.

49 Mansilla y Huaiquián, "Enseñanza a la alemana”.
} 
La "negación" se comprende como un proceso asociado a una hegemonía de poder y de saber occidental que niega y elimina al sujeto de saber y conocimiento propio. De este modo, al sujeto mapuche se le condicionó para asumir un estado de inferioridad en el sistema escolar. Por otra parte, el "ocultamiento" es una estrategia que induce a los niños y jóvenes que dominan saberes y conocimientos sobre las características socioculturales propias a ocultarlos en forma consciente o inconsciente.

Por ende, los estudiantes de ascendencia mapuche en el periodo post-reduccional fueron sedimentando - producto de su escolarización - la duda, el olvido, la desvalorización e invisibilización de los conocimientos y saberes propios: del mapun-kimün ante un conocimiento escolar se presentó como válido para desarrollar y movilizar competencias individuales y sociales. En este proceso, el mapunzugun, como lengua de comunicación de los estudiantes mapuche, debía ser suprimido. Desde esta lógica, los profesores de la escuela occidental monocultural chilena fueron los primeros agentes de discriminación, injusticia y negación de la lengua y cultura ancestral ${ }^{50}$.

Para la fundamentación del problema de investigación, precisamos los siguientes conceptos principales y enfoques: escuela colonizadora republicana chilena; el enfoque monocultural; escuela indígena desde el enfoque cultural e intercultural; y escuela/educación mapuche, desde el mapun-kimün.

La escuela y su perspectiva colonizadora republicana chilena, institución que organiza la enseñanza y el aprendizaje jerárquicamente, limitando y reprimiendo las diversas formas de aprehensión de la realidad. El currículo disciplinario de la escuela monocultural chilena fabricó cuerpos sometidos y ejercitados, dóciles al amparo de la invención de una nueva anatomía política, que se tradujo en una multiplicidad de procesos, con frecuencia menores, de origen diferente, de localización diseminada, que coinciden, se repiten o imitan, se apoyan unos sobre otros, convergen y delinean. Su espacio privilegiado de actuación temprana fueron las escuelas, liceos e internados. La disciplina, como anatomía política del detalle, operó desde la minucia de los reglamentos, la enseñanza, el aprendizaje, la teoría pedagógica, las burocracias, inspecciones, poner bajo control las menores partículas de la vida y del cuerpo al amparo una racionalidad técnica ${ }^{51}$.

Laescuela/educación indígena. Por epistemología educativa indígena se entiende la manera en la que un grupo cultural desarrolla formas de pensar y crear, reformular y teorizar sobre el conocimiento por medio de discursos tradicionales y medios de comunicación (la escuela), anclando la verdad del discurso en la cultura $^{52}$. Los tres puntos capitales de la educación de los pueblos originarios son: (1) el valor de la tradición (2) el valor de la acción, y, (3) el ejemplo, esto es, el sentido del legado de los antepasados y el contenido práctico de las tradiciones.

La escuela desde la concepción mapuche, especialmente desde la historia y memoria oral, la visión de mundo se visualiza en las nociones de: mapun, fuerza

50 Mansilla et al., "Instalación de la escuela monocultural".

51 Michel Foucault, Las palabras y las cosas. Una arqueología de las ciencias humanas (Buenos Aires: Siglo XXI, 2008), 201.

52 Becerra y Llanquinao, Mapun kimün. Relaciones mapunche. 
espiritual que creó a la tierra, el territorio, las cosas y la vida; el chen, como fuerza espiritual que creó a las personas; el mogen, fuerza espiritual que creó el agua, animales, alimentos, aire, vientos y todo objeto material e inmaterial que sustenta el ser mapuche en su territorio histórico ${ }^{53}$. El conocimiento educativo mapuche implica reconocer: (1) inatuzugu, que significa estudiar e indagar en el conocimiento que ya existe, con el fin de lograr una comprensión de procesos, hechos, sucesos e interpretar la realidad desde una racionalidad propia; (2) nampülkan, que es una racionalización y representación del viaje por el territorio, como también una forma de interpretar la memoria individual y social; (3) mümülkan, que es la racionalización de los procesos de construcción de conocimientos respecto de un objeto; $\mathrm{y},(4)$ zapilüwün, que se refiere a una necesidad de cultivarse en el conocimiento, contribuyendo al aprendizaje y comprensión del desarrollo de las cosas y de las propias personas, como producto que se cultiva en el contexto cultural de la persona, lo cual encierra intereses, contenidos y finalidades educativas.

\section{Método}

Esta investigación se plantea desde un paradigma comprensivo-interpretativo, cuyo método se enlaza con el tipo de investigación cualitativa, aplicada a la historiografía, considerando fuentes escritas. Se desarrolla un análisis documental a partir de un muestreo empírico de material basado en fuentes escritas primarias, secundarias y documentos personales inobstrusivos ${ }^{54}$. Se realizó principalmente trabajo de archivo en las regiones del Biobío, la Araucanía, Los Ríos y Metropolitana, cuya revisión implicó el estudio de los siguientes documentos: (a) prensa escrita nacional y local; (b) documentos jurídicos; (c) discursos de la época; (d) registros de testimonios; (e) reglamentos escolares; (f) fotografías; (g) informes de congresos y seminarios desarrollados en el periodo.

Del mismo modo, en Temuco se revisaron cajas documentales en las unidades de estudio en el Archivo Regional de la Araucanía, a saber: Fondo Intendencia de Cautín: Decretos, comunicaciones recibidas [1929-1973]; oficios despachados [1929-1973]; telegramas despachados [1929-1973] y, finalmente, material existente en el Fondo del Archivo General de Asuntos Indígenas. El trabajo contempló tres fases diferenciables en el proceso de producción de resultados: (1) revisión crítica de los datos de nuestras investigaciones anteriores, además de la revisión bibliográfica de resultados de investigación respecto a la presencia de la escuela en otros pueblos indígenas de América; (2) captura y tratamiento de nuevos datos; y (3) validación y devolución de resultados con los participantes de la investigación ${ }^{55}$.

53 Armando Marileo Lefio y Ricardo Salas Astrain, "Filosofía Occidental y Filosofía Mapuche. Iniciando un Diálogo", Revista ISEES, n. ${ }^{\circ} 9$ (2011): 120.

54 María José Rodríguez Jaume y José Ignacio Garrigós, Análisis sociológico con documentos personales (Madrid: Centro de Investigaciones Sociológicas, 2017), 34.

55 Matthew B. Miles, Michael Huberman y Johnny Saldaña, Qualitative Data Analysis: A Methods Sourcebook (California: Thousand 
Si bien estas fases son secuenciales, existe superposición temporal de tareas, ya que se obtienen resultados acumulativos a través del estudio. No obstante, se contemplaron los siguientes procedimientos: etapa exploratoria-revisionista, a partir de la recolección, catalogación y lectura profunda de las fuentes escritas; y etapa documental, en la que se examinaron sistemáticamente las fuentes, consideradas para el nivel de abstracción trabajado.

\section{CONCLUSIONES}

Conocer los orígenes históricos de la escuela estatal chilena en territorio mapuche, y los conflictos en su etapa fundante, nos ayudará a comprender muchos de los problemas actuales del funcionamiento del sistema educativo.

El Estado asumió el rol de extender el sistema educativo de la nación chilena a los habitantes del wajmapu. No obstante, este proyecto colonizador no consideró las especificidades culturales y políticas del pueblo mapuche, ni tampoco se hizo cargo del intenso proceso de mestizaje entre indígenas y chilenos que en efecto ocurrió en el territorio mapuche. La acción estatal respondió principalmente a los intereses de la elite de Santiago, que buscaba implementar un sistema educativo uniforme y homogeneizante para toda la población, haciendo caso omiso de las particularidades locales y culturales, y que tuvo como telos educativo agudizar la división social del trabajo. En consecuencia, la escuela se integró discursivamente al proyecto de Estado-Nación implementado en la Frontera desde fines del siglo XIX: la modernización entendida como la "moralización" o la "chilenización" del individuo, fue parte nuclear de la labor civilizadora de la escuela. En otras palabras, el estado de Chile inventó la nación chilena, y no fue la nación chilena la que se transformó en Estado.

El establecimiento de los estados que se suponen post-coloniales en América Latina, Asia y África después de los diversos procesos de descolonización, no trajo consigo modificaciones sustanciales ni estructurales de las relaciones de sometimiento y asimetrías culturales de los pueblos antes colonizados por Estados, en su mayoría europeos. La generación de una identidad no colonial es uno de los objetivos principales de la descolonización a niveles teórico y práctico, sin caer en tendencias esencialistas en, desde y para los pueblos originarios.

En esta perspectiva, lo nuevo que aporta esta investigación es el conocimiento de base documental referido a la constitución de la escuela en la Araucanía post-reduccional del territorio mapuche como agencia principal de la República colonial chilena. Esto permitirá profundizar y develar los orígenes de los problemas vinculados a la subestimación del idioma materno, las relaciones interculturales y choque cultural del mapun-kimün y saberes propios de la sociedad eurocéntrica occidental, aportando nuevos conocimientos asociados

Oaks / Sage Publications, 2014), 97. 
a la historia de la educación. También contribuirá como una base de conocimientos de fuentes, generando conocimiento base para la formación inicial de profesores y para aquellos/as que se desempeñan profesionalmente en escuelas situadas en territorios con una alta densidad de población indígena. Asimismo, contribuye al rescate de la memoria, así las futuras personas mapunche y no mapuche comprenderán la génesis de las actuales tensiones interculturales que existen en las escuelas y liceos que se sitúan en el waj-mapu.

\section{REFERENCIAS}

Becerra, Rodrigo y Gabriel Llanquinao, editores. Mapun kimün. Relaciones mapunche entre persona, tiempo y espacio. Santiago de Chile: Ocho Libros, 2018.

Bengoa, José. Historia de los antiguos mapuches del sur. Desde antes de la llegada de los españoles hasta las paces de Quilín. Santiago de Chile: Catalonia, 2003.

Bengoa, José, compilador. La memoria olvidada: historia de los pueblos indígenas de Chile. Santiago de Chile: Cuadernos Bicentenario de la Presidencia de la República, 2004.

Bengoa, José. El Tratado de Quilín. Documentos adicionales a la Historia de los antiguos mapuches del sur. Santiago de Chile, Catalonia, 2007.

Boccara, Guillaume, editor. Colonización, resistencia y mestizaje en las Américas. Siglos XVI-XX. Quito: Abya-Yala, 2002.

Boloña, Nicanor. "Carta general de colonización de la Provincia de Cautín". Archivo Regional de la Araucanía, Temuco. Inspección general de Colonización e Inmigración. Escala 1:100.000. Santiago de Chile, septiembre de 1916.

Bourdieu, Pierre y Jean-Claude Passeron. Los herederos. Los estudiantes y la cultura. Buenos Aires: Siglo XXI, 2008.

Calbucura, Jorge. “La decolonización del saber y el ser mapuche: un caso de estudio al celebrarse el bicentenario de la construcción de la República de Chile". Polis. Revista Latinoamericana 12, n. ${ }^{\circ} 35$ (2013): 415-427. https://scielo.conicyt.cl/pdf/polis/v12n35/art18.pdf

Casanueva Valencia, Fernando. “Indios malos en tierras buenas: visión y concepción del mapuche según las élites chilenas, siglo XIX. En Colonización, resistencia y mestizaje en las Américas. Siglos XVI-XX, editado por Guillaume Boccara. Quito: Abya-Yala, 2002.

Castro-Gómez, Santiago. La poscolonialidad explicada a los niños. Popayán: Editorial Universidad del Cauca / Universidad Javeriana, 2005.

De Amberga, Jerónimo. "Estado intelectual, moral y económico del araucano". Revista chilena de historia y geografía 7, n. ${ }^{\circ} 11$ (1911): 5-37.

De Jong, Ingrid y Antonio Escobar Ohmstede, coordinadores y editores. Las poblaciones indígenas en la conformación de las naciones y los Estados en la América Latina decimonónica. Ciudad de México: El Colegio de México / Centro de Investigaciones y Estudios Superiores en Antropología Social / El Colegio de Michoacán, 2016.

De Sousa-Santos, Boaventura. Conocer desde el Sur: Para una cultura política emancipatoria. La Paz: CIDES-UMSA / CLACSO / Plural, 2008.

Donoso Romo, Andrés. Educación y nación al sur de la Frontera: Organizaciones mapuche en el umbral de nuestra contemporaneidad, 1880-1930. Santiago de Chile: Pehuén, 2010.

Durán, Teresa, Desiderio Catriquir y Arturo Hernández, compiladores. Patrimonio cultural mapuche: Derechos sociales y patrimonio institucional mapuche. Temuco: Universidad Católica de Temuco, 2007.

Essomba, Miquel. Construir la escuela intercultural: reflexiones y propuestas para trabajar la diversidad étnica y cultural. Barcelona: Graó, 1999.

Estermann, Josef. “Colonialidad, descolonización e interculturalidad. Apuntes desde la Filosofía Intercultural". Polis: Revista Latinoamericana 13, n. ${ }^{\circ} 38$ (2014): 347-368.

Flores, Jaime y Alonso Azócar. Evangelizar, civilizar y chilenizar a los mapuches. Fotografías de la acción 
de los misioneros capuchinos en la Araucanía. Temuco-Sevilla: Ediciones Universidad de La Frontera / Editorial Universidad de Sevilla, 2015.

Foote, Susan A. Pascual Coña: Historias de sobrevivientes. La voz en la letra y la letra en la voz. Concepción: Editorial Universidad de Concepción, 2012.

Foucault, Michel. Las palabras y las cosas. Una arqueología de las ciencias humanas. Buenos Aires: Siglo XXI, 2008.

Gavilán, Víctor. La Nación mapuche. Puelmapu ka Gulumapu. Santiago de Chile: Ayun, 2007.

Gruzinski, Serge. La colonización de lo imaginario: Sociedades indígenas y occidentalización en el México español. Siglos XVI-XVIII. México: Fondo de Cultura Económica, 1991.

Llancavil, Daniel, Juan Mansilla, Manuel Mieres y Elizabeth Montanares. “La función reproductora de la escuela en la Araucanía, 1883-1910". Revista Austral de Ciencias Sociales, n. ${ }^{\circ} 28$ (2015): 117-135. https://doi.org/10.4206/rev.austral.cienc.soc.2015.n28-07

Mansilla, Juan, Gabriel Pozo, Margarita Canio y Johanna Umbach. La cruz capuchina en territorio mapuche. Educación y memoria fotográfica en Altötting, Alemania. Santiago de Chile: Pehuén, 2020.

Mansilla, Juan y Claudia Huaiquián. “Enseñanza a la alemana: Transferencia del modelo de escuela de Berlín a Chile a fines del siglo XIX". Revista Espacios 17, n. 39 (2018): 1-9.

Mansilla, Juan, Daniel Llancavil, Manuel Mieres y Elizabeth Montanares. “Instalación de la escuela monocultural en la Araucanía, 1883-1910: dispositivos de poder y Sociedad Mapuche". Educação e Pesquisa 42, n. ${ }^{1}$ (2016): 213-228. http://dx.doi.org/10.1590/S15179702201603140562

Marileo, Armando y Ricardo Salas. "Filosofía Occidental y Filosofía Mapuche: Iniciando un Diálogo", Revista ISEES, n. ${ }^{\circ}$ (2011): 119-138.

Menard, André y Jorge Pavez, editores. Mapuche y anglicanos. Vestigios fotográficos de la Misión Araucana de Kepe, 1896-1908. Santiago de Chile: Ocho Libros, 2007.

Miles, Matthew, Michael Huberman y Johnny Saldaña. Qualitative Data Analysis: A Methods Sourcebook. California: Thousand Oaks / Sage Publications, 2014.

Millamán, Rosamel. "Relaciones interraciales e interétnicas de mapuches con no mapuches". En Rostros y fronteras de la identidad, compilado por Mario Samaniego y Carmen Gloria Garbarini. Temuco: Pehuén editores, 2010, 27-42.

Nahuelpan Moreno, Héctor y Jaime Antimil Caniupan. "Colonialismo republicano, violencia y subordinación racial mapuche en Chile durante el siglo XX". Historelo. Revista de historia regional y local 11, n. ${ }^{\circ} 21$ (2019): 211-248. http://dx.doi.org/10.15446/historelo.v11n21.71500

Ortiz, Carolina. "Felipe Guamán Poma, Clorinda Matto de Turner, Trinidad Enríquez y la teoría crítica". En Des/colonialidad y bien vivir. Un nuevo debate en América Latina, editado por Aníbal Quijano. Lima: Editorial Universidad Ricardo Palma, 2014.

Paillalef, Julio. Los mapuche y el proceso que los convirtió en indios. Santiago de Chile: Universidad Tecnológica Metropolitana, 2003.

Palumbo, María. “Educación En Movimientos Populares Rurales: Un Estado del Arte". Revista Historia de la Educación Latinoamericana vol.18 n. ${ }^{\circ}$ 26, (2016) 219-40. https://doi. org/10.19053/01227238.4373.

Pinto Rodríguez, Jorge. De la inclusión a la exclusión: La formación del Estado, la nación y el pueblo mapuche. Santiago de Chile: Idea, 2001.

Pozo, Gabriel, editor. Expoliación y violación de los derechos humanos en territorio mapunche. Cartas del padre Sigifredo, Misión de Panguipulli, año 1905. Santiago de Chile: Ocho Libros, 2018.

Quidel, José. El quiebre ontológico a partir del contacto mapuche hispano. Chungara - Revista de Antropología Chilena 48, n. 4 (2016): 713-719. https://scielo.conicyt.cl/pdf/chungara/v48n4/ art07.pdf

Quilaqueo, Daniel, Segundo Quintriqueo y Prosperino Cárdenas, editores. Educación, currículum e interculturalidad: Elementos sobre formación de profesores en contexto mapuche. Santiago de Chile: Frasis, 2005.

Quintriqueo, Segundo y Margaret McGinity Travers. "Implicancias de un modelo curricular monocultural en la construcción de la identidad sociocultural de alumnos mapuches de la IX Región de la Araucanía, Chile". Estudios Pedagógicos, 35, n. 2 (2009): 173-188. 
Rodríguez, María José y José Ignacio Garrigós. Análisis sociológico con documentos personales. Madrid: Centro de Investigaciones Sociológicas, 2017.

Schiwy, Freya. “¿Intelectuales subalternos?: notas sobre las dificultades de pensar en diálogo intercultural". En Indisciplinar las ciencias sociales. Geopoliticas del conocimiento y colonialidad del poder. Perspectivas desde lo andino, editado por Catherine Walsh, Freya Schiwy y Santiago Castro-Gómez. Quito: Abya-Yala, 2002.

Serrano, Sol, Macarena Ponce de León y Francisca Rengifo, editoras. Historia de la Educación en Chile (1810-2010). Tomo II: La educación nacional (1880-1930). Santiago de Chile: Taurus, 2012.

Szulc, Andrea. "Concepciones de niñez e identidad en las experiencias escolares de niños mapuche del Neuquén", Anthropologica 23, n. ${ }^{\circ} 35$ (2015): 235-253.

Tubino, Fidel. "El nivel epistémico de los conflictos interculturales", Revista Electrónica Construyendo Nuestra Interculturalidad $6 \mathrm{n} .^{\circ} 7$ (2011): 1-14.

Tuhiwai, Linda. A descolonizar las metodologías: Investigación y pueblos indígenas. Santiago de Chile: LOM ediciones, 2016.

\section{Cómo citar:}

Mansilla Sepúlveda, Juan. “República colonial chilena 1929-1973.

Escuela e invisibilización del mapun-kimun del pueblo nación mapuche". Revista Historia de la Educación Latinoamericana. 22

No. 35 (2020): 145-162

https://doi.org/10.19053/01227238.11925

(c) (i) @ E Reconocimiento-No Comercial-Sin Obra Derivada 2.5 Colombia. 